УДК 378.147:004+378.014.3

\title{
ДИСТАНЦИОННОЕ ОБУЧЕНИЕ И МОДЕРНИЗАЦИЯ ОБРАЗОВАНИЯ - ТУПИК ИЛИ ВОзМОЖНОСТЬ?
}

\author{
Левин Семен Михайлович, \\ levin.sm@asu.tusur.ru \\ Томский государственный университет систем управления и радиоэлектроники, \\ Россия, 634050, г. Томск, пр. Ленина, 40.
}

\begin{abstract}
Левин Семен Михайлович, кандидат юридических наук, профессор кафедры автоматизированных систем управления факультета систем управления Томского государственного университета систем управления и радиоэлектроники.
\end{abstract}

В статье рассматриваются вопросы дистанционного обучения с позиции реализации студентоцентрированного образовательного процесса - одного из принципов Болонской декларации. Актуальность исследований в этой области обусловлена стремительным ростом числа вузов, реализующих дистанционные образовательные программы, который происходит на фоне модернизации системы высшего образования в соответствии с требованиями Болонского процесса. Цель - изучение учебного процесса, протекающего в электронной образовательной среде, выявление проблемных аспектов и поиск эффективных решений для реализации дистанционного обучения на основе современных педагогических концепций. В этой области выявлен ряд проблем, связанных с реформой высшего образования, соблюдения образовательных стандартов, а также развитием дистанционного образования как формы подготовки квалифицированных специалистов. К указанным проблемам отнесены низкая познавательная самостоятельность студентов, смещение акцента мотивации преподавателей в сторону научно-исследовательской деятельности, профессиональная неподготовленность последних для эффективного применения современных педагогических технологий и инструментов электронных образовательных систем, а также недостаточная наполненность требуемыми элементами самих систем управления обучением. Результаты работы отражены в конкретных рекомендациях по решению проблем в части, регулируемой высшими учебными заведениями: развитие познавательной самостоятельности студентов через использование соответствующих педагогических подходов, изменение системы мотивации профессорскопреподавательского состава, направленной на применение в образовательном процессе современных педагогических технологий, а также формирование компетенций в области электронных образовательных инструментов.

Ключевые слова: Дистанционное обучение, студентоцентрированное образование, личностно ориентированное обучение, Болонский процесс, реформа образования, системы управления обучением.

\section{Введение}

Большинство статей о дистанционном образовании, написанных после весны 2020 г., обязательно упоминают пандемию COVID-19 и вызванные этим изменения. Нет смысла отрицать очевидное - вынужденное социальное дистанцирование и удалённое обучение изменили долю дистанционно преподаваемых дисциплин в общем объёме рынка образовательных услуг и сфокусировали внимание общества на этом явлении [1]. Согласно расхожему мнению, удалённое образование возникло примерно в то же время, что и всемирная паутина, а потому сегмент новый и слабоизученный, имеющий малый практический опыт. 
Разочаровывая сторонников этого заблуждения, напомним, что история удалённого обучения - как мы его понимаем сегодня - берёт начало ещё в середине XIX в., когда Исаак Питман начал преподавать систему стенографии, отправляя по почте открытки с текстами, расшифрованными в стенограммах, и получая от учеников транскрипции текстов в обмен на внесённые исправления. Первая телетрансляция как элемент дистанционного образования была применена впервые Университетом Хьюстона ещё в 1953 г., а программное обеспечение - Университетом Альберты в 1968-м [1]. Уже в 1985 г. Юго-Восточный Университет США предлагал аккредитованные дипломы, полученные в режиме онлайн-обучения, а в 1993 г. был основан Международный университет Джонса - первый университет, работавший полностью в дистанционном формате.

Последующее развитие Интернета обеспечило возможность ускоренного распространения дистанционной формы образовательного процесса. Многолетний опыт обучения студентов в подобной форме сформировал определённую практику адаптации и применения педагогических методик в дистанционном обучении. Безусловно, объём такого опыта в системе образования того или иного государства напрямую зависит от распространённости дистанционной формы и исторической продолжительности её применения.

\section{Концепция учения и современные реалии}

Скорость распространения дистанционного образования зависит от условий среды, включая спрос на подобное обучение и его законодательную обеспеченность. В качестве примера отметим, что до пандемии COVID-19 объём дистанционных курсов в США, в рамках высшего и дополнительного образования, превысил 30 \% об общего объёма образовательных услуг. Примерно в это же время объём аналогичных образовательных услуг в России составлял около 1,1 \% [1]. Лавинообразный переход к обязательному или рекомендательному удалённому обучению в различных странах изменил показатели распространённости дистанционной формы образования и уменьшил разрыв между ними по крайней мере на данном этапе. Можно предположить, что по окончании административных ограничений число обучающихся дистанционно уменьшится, однако полного возврата к показателям доковидной эпохи ждать не стоит. Скорее всего, оно будет реализовано и востребовано в той мере, в которой сможет дать студентам профессиональное образование в объёме и с качеством, которых требуют современные образовательные стандарты и рынок труда. Соответствие этим требованиям обеспечивается такими факторами, как актуальность формируемых знаний, следование конструктивным концепциям и методикам преподавания, а также эффективное применение педагогических инструментов, в том числе электронных.

Парадигма учения, усиленная современными педагогическими технологиями, смещает акценты образовательного процесса и изменяет представлением о том, как именно он должен быть реализован [2]. Одна из ключевых черт парадигмы - академическая свобода учащегося, означающая, в том числе, превалирование индивидуальной формы обучения над коллективной. В контексте статьи под индивидуальной формой подразумевается личностно ориентированное обучение, определяемое педагогической философией конструктивизма - основополагающей идеей современного непрерывного профессионального образования. Задачи педагогики, основанные на постулатах Льва Выготского и Жана-Жака Пияже, сформулированы сегодня как необходимость раскрытия возможностей каждого учащегося и обучение последнего решению проблем при одновременном сохранении процесса непрерывного совершенствования [3, 4]. Концепция учения, основанная на философии конструктивизма, отрицает эффективность пере- 
дачи знаний в готовом виде. Она подразумевает создание благоприятной среды для студентов, которые, в свою очередь, будут конструировать знания для самих себя, формируя собственный смысл обучения.

Изложенное выше - не абстракция. Напомним, что более 20 лет назад была подписана Болонская декларация, ознаменовавшая начало самой глубокой и крупномасштабной реформации высшего образования в Европе [5]. По состоянию на сегодня участниками процесса, названного в честь места подписания Болонским, являются 48 стран, включая Россию. Наряду с контролем качества образования, расширением академической мобильности и обеспечением трудоустройства выпускников важную роль в Болонском процессе играет парадигма так называемого «студентоцентрированного» образования [6], которое может быть реализовано при условии перехода к парадигме учения. М.А. Иванова в своих исследованиях констатирует, что «российское высшее образование находится пока очень далеко и от реализации студентоцентрированного учения» [7]. В качестве одной из причин приводится проблема познавательной самостоятельности студентов, уходящая корнями в школьное образование и проявляющаяся в отсутствии навыков самостоятельной работы, что влечёт неспособность самостоятельной постановки целей, а также неумение брать ответственность за их достижение. Следует согласиться, что порядок реформации системы высшего образования в России напоминает установку телеги впереди лошади или, по крайней мере, сбоку - изменения в большей степени затронули вузы, сохранив уходящую в прошлое парадигму обучения в школах. Отметим, что в большинстве стран Европы реформа школьного образования предшествовала реформе высшего, что позволило воспитать будущих студентов с ориентиром на изменения и нововведения в области университетского образования и в дальнейшем эффективно реализовать принципы Болонской декларации. В случае с российскими вузами преподавателям приходится иметь дело с результатами школьного образования, не учитывающего реформацию высшего.

Перефразируя известное высказывание, отметим, что «других студентов у нас нет». Де-факто это вменяет российским учреждениям высшего образования коррекционную педагогическую функцию. Действительно, теоретически вузы могут внести поправки в результаты школьного образования, сфокусировав образовательный процесс на создании требуемой среды обучения и применении современных педагогических технологий. Однако негативные последствия реализации реформы не обошли стороной и профессорско-преподавательский состав. Повышение требований к отчётности, сопровождающей изменения, привело к возрастанию роли бюрократии в высших учебных заведениях [8] - преподаватели вынуждены оформлять бесчисленное количество документов в своей повседневной деятельности, уменьшая степень внимания к основным функциям своей деятельности. К тому же гонка за повышением рейтинга вуза, помимо реализации принципов Болонского процесса, сконцентрировала внимание профессорско-преподавательского состава на научно-исследовательской работе. Педагогическая составляющая реализовывается порой по остаточному принципу. В результате вузу не удаётся компенсировать недостатки школьного образования, создавая условия для студентоцентрированного обучения и реализуя его на практике, что способствует увеличению бреши между конечными навыками студентов и требованиями рынка труда к квалификации специалистов.

Таким образом, на практике мы получаем модель отношений «студентпреподаватель», в которой у первого отсутствуют определённые качества, необходимые в условиях изменяющейся системы обучения, а у второго нет времени и мотивации, чтобы это исправить. Контроль самостоятельной деятельности студентов зачастую 
сводится к проверке сданной работы на предмет наличия и зачёту её результатов, не обращая внимания, как и кем именно она была выполнена. Справедливости ради стоит обратить внимание и на критерии эффективности работы преподавателей и кафедр вузов. В большей массе они имеют отношение к научно-исследовательской работе и в гораздо меньшей - к процессу обучения. Поэтому обвинять педагогов не стоит - отсутствие соответствующей мотивации обуславливается существующими критериями и приоритетами, формируемыми вне поля их ответственности. Тем не менее несмотря на такой дисбаланс, в образовательном процессе вузов постепенно находят своё практическое отражение как парадигма учения, так и сопровождающие её педагогические технологии. Всё чаще можно увидеть проектное и модульное обучение, кейсы, портфолио [9-12] и т. п. в арсенале учебных планов по дисциплинам различных российских университетов. Конечно, внедрение новых методик и электронных инструментов местами сопряжено с неприятием со стороны преподавателей. Это вызвано как определённым сопротивлением неизбежно наступающему будущему, так и отсутствием необходимых компетенций.

\section{Педагогические технологии и дистанционное образование}

Возвращаясь к вопросу дистанционного обучения, следует сказать, что в зависимости от конечной эффективности оно может стать как перспективной альтернативой очному, так и тупиковой ветвью педагогической эволюции. Опуская вопрос доверия к результатам контроля знаний - это тема отдельной статьи - вернёмся к принципу студентоцентрированного обучения и конструктивизму.

Очевидно, что нельзя ставить знак равенства между очной и дистанционной формами. Собственно, задача дистанционного образования не состоит в точном моделировании очного формата образования, а сводится к реализации педагогических концепций и методов в иных условиях. Не стоит ожидать внезапного чуда: любые платформы управления обучением (Learning Management System - LMS) и составляющие их элементы - лишь инструменты педагогики $[13,14]$, иногда весьма продуктивные, однако они не могут заменить учителей. Организация учебного процесса с использованием технологий дистанционного обучения, формирование курса, наполнение его учебными элементами и, наконец, реализация процесса учения - задача обучающего. Использование современных педагогических методик неразрывно связано с парадигмой учения. Как уже говорилось выше, вместо передачи информации учащимся преподаватель должен формировать условия для конструирования студентами собственных знаний. При этом личностно ориентированный подход к обучению становится центральным элементом большинства сценариев педагогических технологий. Его основные элементы - осмысление деятельности, постановка личной цели, план деятельности, реализация плана, рефлексия, оценка, корректировка или переопределение целей - ядро, вокруг которого наращивается контент учебной программы [15]. Применение данного подхода обязывает обучающего владеть соответствующими образовательными методиками и инструментами электронной образовательной среды.

При дистанционной форме образования большая нагрузка должна приходиться на асинхронные элементы. Конус Эдгара Дэйла (см. рисунок), модифицированный его последователями, свидетельствует о малой эффективности лекций при их высоком уровне абстракции [16]. Сопутствующие вебинарам презентации увеличивают уровень восприятия материала, однако показатель объёма запоминаемого материала остаётся в пределах 30 \% от изложенного. Большей эффективностью обладают наблюдение за конкретным действием, участие в дискуссии и имитация реальной деятельности. Это, в 
свою очередь, обуславливает включение в учебный процесс технологии критического мышления, кейсов, технологии сотрудничества и пр.

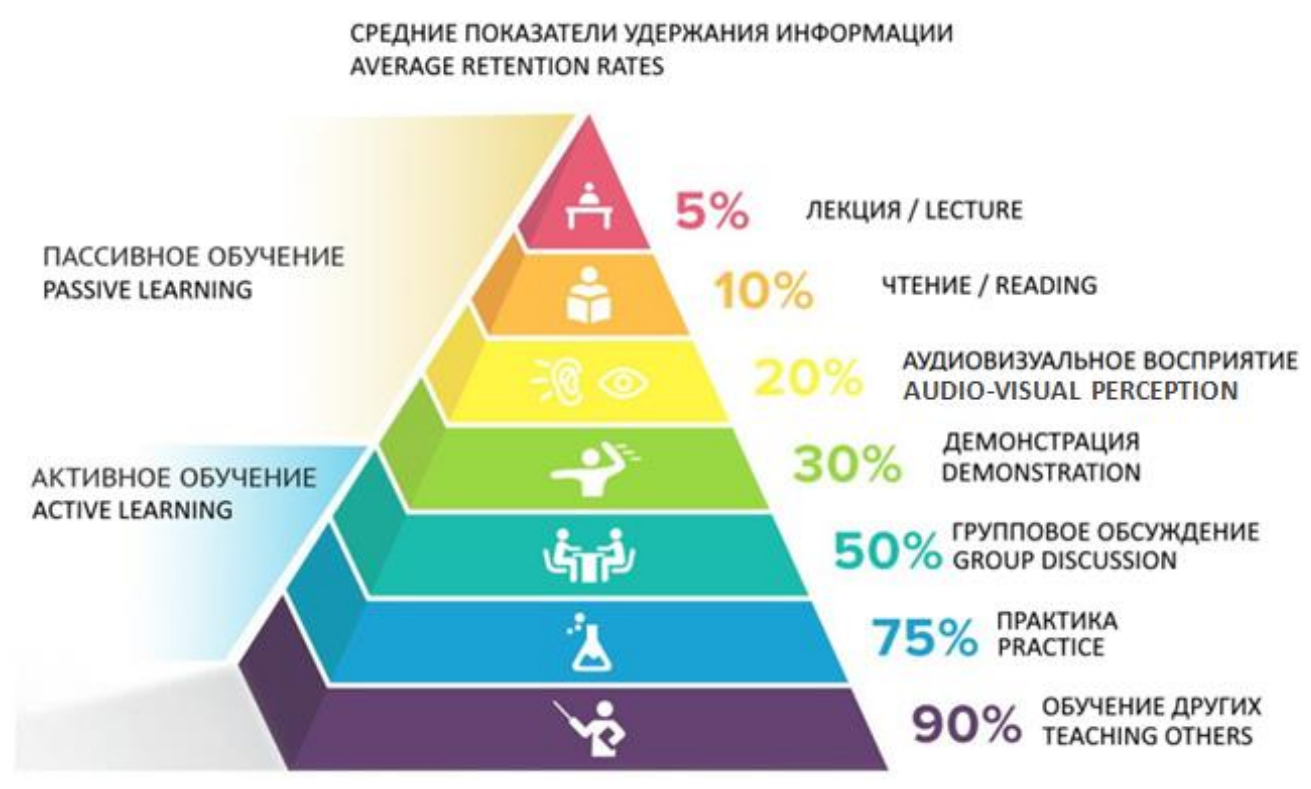

Рисунок. Конус (пирамида) Эдгара Дэйла

Figure. Edgar Dale's Cone (Pyramid)

Многие европейские университеты, практикующие дистанционное образование, придерживаются принципа продуктивности обучения при относительно небольшом числе вебинаров. Доля практических занятий и асинхронных образовательных составляющих заметно превышает лекционный объём. Личные кабинеты студентов на платформах LMS наполнены дискуссиями, индивидуальными заданиями, групповыми проектами. Широко применяются сторонние ресурсы, компенсируя ограниченность используемых систем. Например, некоторые инженерные университеты используют интерактивные инструменты, позволяющие студентам в электронном виде оценить свои знания в области химии, а также провести различные химические опыты, не выходя из комнаты в кампусе. В ряде университетов практикуется индивидуальное планирование обучения в рамках общей учебной программы. Студенты определяют цели и ключевые точки, исходя из своих приоритетов, самооценки и общих сроков изучения той или иной дисциплины. Выявление индивидуальных особенностей и предпочтений учащихся реализуется посредством простых ресурсов образовательных платформ. Используя элементы LMS, преподаватель в начале учебного курса создаёт задание, согласно которому учащийся должен назвать одним-двумя словами основные ожидания от курса, а затем раскрыть их в форме описания. Эти и многие другие примеры свидетельствуют о понимании концепции современного образования, её квалифицированном применении и компетентном обращении с инструментами дистанционного образования. При таком подходе студент находится в субъект-субъектных отношениях и активно участвует в образовательном процессе.

Однако далеко не все вузы могут похвастаться успехами в реализации принципов Болонского процесса, особенно при обучении в дистанционной форме. Многие LMS университеты, и российские - не исключение, содержат курсы с весьма скудным набором педагогических методик и вспомогательных элементов. Вниманию студентов предлагаются вебинары, учебно-методические материалы для самостоятельного изуче- 
ния, а также традиционные индивидуальные задания, далёкие от практики. Преподавание при этом следует парадигме обучения, фактически исключая распространение реформы высшего образования на дистанционных студентов.

Отдельно следует отметить и владение элементами LMS. Для дистанционного применения той или иной педагогической технологии требуется квалифицированное знакомство с ресурсами используемой образовательной платформы [17]. В случаях, когда в рамках учебного курса преподаватель использует два-три учебных элемента, продуктивность подобного обучения снижается.

Безусловно, не всё так однообразно серо на пространстве удалённого образования. Некоторые университеты переносят успешно применяемые методы на платформы дистанционного обучения или адаптируют современные педагогические технологии к изменившимся условиям преподавания. Например, Высшая школа экономики успешно реализует дополнительные профессиональные программы на платформе LMS, базируясь на собственном богатом методологическом арсенале. Также можно отметить Томский государственный университет систем управления и радиоэлектроники, внедряющий современные педагогические технологии в дистанционных программах бакалавриата и магистратуры. Однако в нынешних реалиях образования подобные примеры лишь подчёркивают контраст превалирующего несоответствия фактического состояния дел желаемому $[18,19]$.

Сегодняшняя массовость российского дистанционного образования, как и многих других стран, - в большей степени дань пандемии, чем продукт естественного развития. Как результат резкого перехода - неподготовленность. Если дополнить картину проблемами реформы образования, описанными выше, проблемами социализации студентов при удалённом обучении [20], а также субъективными и объективными сложностями в подготовке преподавателей для работы с платформами дистанционного обучения, то она всё равно останется неполной. Отметим, что функционал многих из наиболее распространённых LMS не соответствует в полной мере запросам педагогических методик. Ограниченные возможности студентов в управлении учебным процессом, например отсутствие тайм-менеджмента, планирования, создают границы для поля возможностей, которое меньше поля педагогической необходимости $[13,14]$.

\section{Выводы}

Исследования в области применения дистанционной формы обучения в российских учреждениях высшего образования выявили ряд проблем, четыре из которых описаны в данной статье. Две из них - общего характера, имеющие отношение к специфике реализации принципов Болонского процесса. К ним относятся низкая познавательная самостоятельность студентов как продукт школьного образования, а также неподготовленность и слабая мотивация профессорского-преподавательского состава, обусловленная некоторой деформацией при соблюдении вузами федеральных государственных образовательных стандартов. К проблемам исключительно дистанционного образования следует отнести недостаточную квалификацию преподавателей в части применения инструментов LMS в образовательном процессе, а также ограниченный функционал самих платформ.

Университеты обладают возможностями решить собственными силами часть из описанных проблем, оставив прочие на совести реформаторов образования и производителей систем управления обучением. Вторые, впрочем, более восприимчивы к запросам современного образования, поскольку руководствуются монетарной мотивацией, основанной на требованиях образовательных учреждений. 
Вузы могут способствовать развитию познавательной самостоятельности студентов, применяя в учебных курсах по изучаемым дисциплинам соответствующие педагогические подходы - технологии сотрудничества, групповое обучение, одноранговые пары (peer-2-peer), включая соответствующие формы контроля знаний, и пр. По сути, уже сам переход к парадигме учения создаёт требуемые условия, вынуждающие учащихся к самостоятельной деятельности.

Конечно, одной готовности учащихся недостаточно для получения желаемого результата. Активное участие обучающих - очевидный и неотъемлемый фактор успеха. Сделать его эффективным - значит, перестроить систему мотивации профессорскопреподавательского состава. Педагогическая составляющая должна быть весомой как объёму, так и по содержанию. Без подобных изменений, нацеленных на трансформацию образовательного процесса и обновления используемых методов, бремя реформации и развития различных форм обучения ляжет на плечи немногочисленных энтузиастов, дорожащих честью вуза и отечественного высшего образования больше, чем собственным кошельком.

Также необходимо обеспечить возможность обучения преподавателей пользованию инструментами электронных образовательных систем, усилив это соответствующей позицией в системе мотивации. Эксплуатируемые вузами LMS не могут быть учебными полигонами для преподавателей, в то время как от них ожидается профессиональный уровень владения всем спектром электронных инструментов.

Изменение системы мотивации преподавателей, как и уровня их подготовки в части использования LMS, во многом регулируется каждым конкретным вузом. Учебное заведение, стремящееся выпускать достойных специалистов, в процессе реформации образования не должно забывать о ключевых участниках этой реформы - педагогах. Если театр начинается с вешалки, то университет - с преподавателей. Те из них, кто стремится включать в повседневную практику современные методики преподавания и умеют эффективно обращаться с элементами электронной образовательной среды, действительно способны не только внести позитивные изменения в образовательный процесс вуза, но и сделать дистанционное образование конкурентоспособным инструментом подготовки специалистов.

\section{СПИСОК ЛИТЕРАТУРЫ}

1. Исакова А.И., Кориков А.М., Левин С.М. Платформы взаимодействия со студентами в условиях пандемии COVID-19 и дистанционного обучения // Современное образование: повышение конкурентоспособности университетов. В 2 ч. Ч. 2: материалы междунар. науч.-метод. конф., 28-29 января 2021 г., Томск, Россия. - Томск: Изд-во ТУСУРа, 2021. - С. 189-195.

2. Barr R.B., Tagg J. From teaching to learning - a new paradigm for undergraduate education // Change: The Magazine of Higher Learning. - 1995. - V. 27. - P. 12-26.

3. Лукинова Л.П. Конструктивизм в обучении как активный процесс научного познания // Конструктивизм в психологической и педагогической науке. Сборник статей Международной научнопрактической конференции. - Уфа: ООО «Аэтерна», 2020. - С. 56-58.

4. Пархитько Н.П. Развитие непрерывного образования в России. Проблемы и перспективы // Постсоветские исследования. - 2019. - Т. 2. - № 4. - С. 1210-1216.

5. The Bologna process and the search for excellence: between rhetoric and reality, the emotional reactions of teachers / I.P. Freire, M.T. Estrela, A. Amaral, J.A. Espírito Santo // Teaching in Higher Education. 2017. - V. 22. - Iss. 4. - P. 467-482.

6. Студентоцентрированное обучение. Инструментарий для студентов, профессорскопреподавательского состава и вузов / А. Аттард, Э. Ди Иорио, К. Гевен, Р. Санта. - Астана: НКАОКО-IQАА, 2017. - 64 с.

7. Иванова М.А. Болонский процесс и самостоятельность студентов: российская специфика // Высшее образование в России. - 2018. - Т. 27. - № 3. - С. 48-58. 
8. Байденко В.И., Селезнева Н.А. Нынешний раунд Болонского процесса: сохранение оптимизма. И немного о российском ... (Статья 1) // Высшее образование в России. - 2017. - № 10. - С. 94-108.

9. Трищенко Д.А. Опыт проектного обучения: попытка объективного анализа достижений и проблем // Образование и наука. - 2018. - Т. 20. - № 4. - С. 132-152.

10. Иванова О.В. Опыт использования технологии модульного обучения в вузе средствами Moodle // Образовательные технологии. - 2018. - № 2. - С. 87-99.

11. Бибикова Э.В. Использование кейс-метода на занятиях по иностранному языку в неязыковом вузе // Тенденции развития психологии, педагогики и образования: сборник научных трудов по итогам международной научно-практической конференции. - Казань, 2017. - С. 45-47.

12. Хусаинова Г.Р., Гиниятуллина Д.Р. Метод портфолио для формирования ключевых компетенций будущих инженеров // Проблемы современного педагогического образования. - 2018. - № 60-1. C. 366-369.

13. Левин C.M. Не все LMS одинаково полезны [для обучения] (такое название в истонике, в квадратных скобках)// Национальная ассоциация ученых. - 2021. - Т. 3. - № 66. - С. 22-26.

14. Anirban R. Bhattacharyya. Do learning management systems really manage learning? // Report. The University of Texas at Austin. - 2020. URL: http://dx.doi.org/10.26153/tsw/10932 (дата обращения 10.03.2021).

15. Краевский B.B. Принципы личностно-ориентированного обучения. URL: http://www.elitarium.ru/princip-obuchenie-poznanie-celi-znanija-organizacija-soderzhanie-obrazovanija (дата обращения 11.03.2021).

16. Lee S.J., Reeves T.C. Edgar Dale: a significant contributor to the field of educational technology // Educational Technology. - 2007. - V. 47. - № 6. - P. 56-59.

17. Noreen S. Implementation of learning management system: a way ahead on the digital journey in distance learning // Open Praxis. - 2020. - V. 12. - P. 329-342.

18. Маргарян Т.Д., Дикова О.Д. Болонский процесс в России: проблемы и перспективы // Гуманитарный вестник. URL: http://hmbu.bmstu.ru/catalog/pedagog/hidden/70.htm (дата обращения 11.03.2021).

19. Богуславский М.В. Консервативная стратегия модернизации российского образования в начале XXI века // Педагогика XXI века: стандарты и практики: Материалы Международной научнопрактической конференции. - Липецк: ЛГПУ имени П.П. Семенова-ТянШанского, 2016. - Ч. I. С. 3-10.

20. Левин C.M. Методы улучшения психического здоровья студентов в условиях вынужденного дистанционного обучения и социального дистанцирования // Векторы благополучия: экономика и социум. 2021. - № 1 (40). - C. 66-78. URL: https://jwt.su/journal/article/view/1086/1078 (дата обращения: 19.03.2021).

Поступила 20.03.2021 г. 


\title{
DISTANCE LEARNING AND EDUCATION MODERNIZATION - DEADLOCK OR OPPORTUNITY?
}

\author{
Semen M. Levin, \\ levin.sm@asu.tusur.ru \\ Tomsk State University of Control Systems and Radioelectronics, \\ 40, Lenin avenue, Tomsk, 634050, Russia.
}

Semen M. Levin, Cand. Sc., professor, Tomsk State University of Control Systems and Radioelectronics.

The article discusses distance learning issues from the perspective of the implementation of the studentcentred educational process - one of the principles of the Bologna Declaration. The relevance of research in this area is caused by the rapid growth in the number of universities implementing distance learning programs, which is taking place against the background of the modernization of the higher education system in accordance with the requirements of the Bologna process. The research investigates the educational process in the electronic educational environment, identifies problematic aspects, and finds practical solutions for implementation of distance learning based on modern pedagogical concepts. In this area, the author has identified several problems related to the reform of higher education, compliance with educational standards and development of distance education as a form of training qualified specialists. These problems include the low cognitive independence of students, the shift in the emphasis of teachers' motivation towards research activities, the professional unpreparedness of the latter for the effective use of modern pedagogical technologies and tools of electronic educational systems as well as insufficient filling of the required elements of the learning management systems themselves. The results of the work are reflected in specific recommendations for solving problems in part regulated by higher educational institutions - the development of the cognitive independence of students through the use of appropriate pedagogical approaches, a change in the motivation system of the pedagogues, aimed at the use of modern pedagogical technologies in educational process, as well as the formation of competencies in the field of electronic educational tools.

Key words: Distance learning, student-centred education, student-centred learning, The Bologna Process, educational reform, learning management systems.

\section{REFERENCES}

1. Isakova A.I., Korikov A.M., Levin S.M. Platformy vzaimodeystviya so studentami v usloviyakh pandemii COVID-19 i distantsionnogo obucheniya [Platforms for interaction with students in the context of the COVID19 pandemic and distance learning]. Sovremennoe obrazovanie: povyshenie konkurentosposobnosti universitetov. Ch. 2: materialy mezhdunarodnoy nauchno-metodicheskoy konferentsii [Modern education: increasing the competitiveness of universities. P. 2: Materials of the international scientific and methodological conference]. Tomsk, Russia, January 28-29, 2021. Tomsk, TUSUR Publ. House, 2021. pp. 189-195.

2. Barr R.B., Tagg J. From teaching to learning - a new paradigm for undergraduate education. Change: The Magazine of Higher Learning, 1995, vol. 27, pp. 12-26.

3. Lukinova L.P. Konstruktivizm v psikhologicheskoy i pedagogicheskoy nauke [Constructivism in psychological and pedagogical science]. Sbornik statey mezhdunarodnoy nauchno-prakticheskoy konferentsii [Collection of articles of the International Scientific and Practical Conference]. Ufa, Aeterna Publ., 2020. pp. 56-58.

4. Parkhitko N.P. Razvitie nepreryvnogo obrazovaniya v Rossii. Problemy i perspektivy [Development of lifelong education in Russia. Problems and Prospects]. Post-Soviet Studies, 2019, vol. 2, no. 4, pp. 1210-1216.

5. Freire I.P., Estrela M.T., Amaral A., Espírito Santo J.A. The Bologna process and the search for excellence: between rhetoric and reality, the emotional reactions of teachers. Teaching in Higher Education, 2017, vol. 22, Iss. 4, pp. 467-482. 
6. Attard A., Di Iorio E., Geven C., Santa R. Studentotsentrirovannoe obuchenie. Instrumentariy dlya studentov, professorsko-prepodavatelskogo sostava i vuzov [Student-centred learning. Toolkit for students, faculty and universities]. Astana, NKAOKO-IQAA Publ., 2017. 64 p.

7. Ivanova M.A. Bolonskiy protsess i samostoyatelnost studentov: rossiyskaya spetsifika [The Bologna Process and the independence of students: Russian specificity]. Higher Education in Russia, 2018, vol. 27, no. 3, pp. 48-58.

8. Baydenko V.I., Selezneva N.A. Nyneshniy raund Bolonskogo protsessa: sokhranenie optimizma. I nemnogo o rossiyskom... (Statya 1) [The current round of the Bologna Process: maintaining optimism. And a little about Russian... (Article 1)]. Higher education in Russia, 2017, no. 10, pp. 94-108.

9. Trishchenko D.A. Opyt proektnogo obucheniya: popytka obektivnogo analiza dostizheniy i problem [Project-based learning experience: an attempt to objectively analyze achievements and problems]. Education and Science, 2018, vol. 20, no. 4, pp. 132-152.

10. Ivanova O.V. Opyt ispolzovaniya tekhnologii modulnogo obucheniya v vuze sredstvami Moodle [Experience of using the technology of modular education at the university by means of Moodle]. Educational technologies, 2018, no. 2, pp. 87-99.

11. Bibikova E.V. Ispolzovanie keys-metoda na zanyatiyakh po inostrannomu yazyku v neyazykovom vuze [Using the case method in foreign language classes in a non-linguistic university]. Tendentsii razvitiya psikhologii, pedagogiki i obrazovaniya: sbornik nauchnykh trudov po itogam mezhdunarodnoy nauchnoprakticheskoy konferentsii [Trends in the development of psychology, pedagogy and education. Collection of scientific papers on the results of the international scientific and practical conference]. Kazan, 2017. pp. $45-47$.

12. Khusainova G.R., Giniyatullina D.R. Metod portfolio dlya formirovaniya klyuchevykh kompetentsiy budushchikh inzhenerov [Portfolio method for the formation of key competencies of future engineers. Problems of modern pedagogical education]. Problemy sovremennogo pedagogicheskogo obrazovaniya, 2018, no. 60-1, pp. 366-369.

13. Levin S.M. Ne vse LMS odinakovo polezny [dlya obucheniya] [Not all LMS are equally useful [for learning]]. National Association of Scientists, 2021, vol. 3, no. 66, pp. 22-26.

14. Anirban R. Bhattacharyya. Do learning management systems really manage learning? Report. The University of Texas at Austin, 2020. Available at: http://dx.doi.org/10.26153/tsw/10932 (accessed 10 March 2021).

15. Kraevsky V.V. Printsipy lichnostno-orientirovannogo obucheniya [The principles of student-centered learning]. Available at: http://www.elitarium.ru/princip-obuchenie-poznanie-celi-znanija-organizacijasoderzhanie-obrazovanija (accessed 11 March 2021).

16. Lee S.J., Reeves T.C. Edgar Dale: a significant contributor to the field of educational technology. Educational Technology, 2007, vol. 47, no. 6, pp. 56-59.

17. Noreen S. Implementation of learning management system: a way ahead on the digital journey in distance learning. Open Praxis, 2020, vol. 12, pp. 329-342.

18. Margaryan T.D., Dikova O.D. Bolonskiy protsess v Rossii: problemy i perspektivy [The Bologna Process in Russia: problems and prospects]. Humanitarian Bulletin. Available at: http://hmbu.bmstu.ru/catalog/pedagog/hidden/70.htm (accessed 11 March 2021).

19. Boguslavsky M.V. Konservativnaya strategiya modernizatsii rossiyskogo obrazovaniya v nachale XXI veka [Conservative strategy for modernization of Russian education at the beginning of the XXI century]. Pedagogika XXI veka: standarty i praktiki: Materialy Mezhdunarodnoy nauchno-prakticheskoy konferentsii [Materials of the International Scientific and Practical Conference. Pedagogy of the XXI century: standards and practices]. Lipetsk, Leningrad State Pedagogical University named after P.P. Semenov-Tyanshanskogo Publ., 2016. P. I, pp. 3-10.

20. Levin S.M. Methods for improvement of students mental health in the terms of forced distance learning and social distancing. Journal of Wellbeing Technologies, 2021, no. 1 (40), pp. 66-78. In Rus. Available at: https://jwt.su/journal/article/view/1086/1078 (accessed: 19 March 2021).

Received: 20 March 2021. 